\title{
Light quantity affects the regulation of cell shape in Fremyella diplosiphon
}

\author{
Bagmi Pattanaik ${ }^{1}$, Melissa J. Whitaker ${ }^{1}$ and Beronda L. Montgomery ${ }^{1,2}$ * \\ ${ }^{1}$ MSU-DOE Plant Research Laboratory, Michigan State University, East Lansing, MI, USA \\ ${ }^{2}$ Department of Biochemistry and Molecular Biology, Michigan State University, East Lansing, MI, USA
}

\section{Edited by:}

Wendy Schluchter, University of New Orleans, USA

Reviewed by:

Qingfang He, University of Arkansas Little Rock, USA

Michael Summers, California State

University Northridge, USA

*Correspondence:

Beronda L. Montgomery, MSU-DOE Plant Research Laboratory, Michigan State University, 612 Wilson Road, Room 106, East Lansing, MI 48824, USA.

e-mail: montg133@msu.edu
In some cyanobacteria, the color or prevalent wavelengths of ambient light can impact the protein or pigment composition of the light-harvesting complexes. In some cases, light color or quality impacts cellular morphology. The significance of changes in pigmentation is associated strongly with optimizing light absorption for photosynthesis, whereas the significance of changes in light quality-dependent cellular morphology is less well understood. In natural aquatic environments, light quality and intensity change simultaneously at varying depths of the water column. Thus, we hypothesize that changes in morphology that also have been attributed to differences in the prevalent wavelengths of available light may largely be associated with changes in light intensity. Fremyella diplosiphon shows highly reproducible light-dependent changes in pigmentation and morphology. Under red light $(\mathrm{RL}), \mathrm{F}$. diplosiphon cells are blue-green in color, due to the accumulation of high levels of phycocyanin, a RL-absorbing pigment in the light-harvesting complexes or phycobilisomes (PBSs), and the shape of cells are short and rounded. Conversely, under green light (GL), F. diplosiphon cells are red in color due to accumulation of GL-absorbing phycoerythrin in PBSs, and are longer and brick-shaped. GL is enriched at lower depths in the water column, where overall levels of light also are reduced, i.e., to $10 \%$ or less of the intensity found at the water surface. We hypothesize that longer cells under low light intensities at increasing depths in the water column, which are generally also enriched in green wavelengths, are associated with greater levels of total photosynthetic pigments in the thylakoid membranes. To test this hypothesis, we grew F. diplosiphon under increasing intensities of GL and observed whether the length of cells diminished due to reduced pressure to maintain larger cells and the associated increased photosynthetic membrane capacity under high light intensity, independent of whether it is light of green wavelengths.

Keywords: complementary chromatic adaptation, cyanobacteria, light intensity, light quality, morphology, photobiology

\section{INTRODUCTION}

Due to fluctuations in parameters of the external environment, many biological organisms possess mechanisms for sensing changes in their habitat. An ability to monitor environmental changes is vitally important for organisms that have limited mobility and thus, must optimize their growth and development to maximize survival in the locations in which they find themselves. Photosynthetic organisms are particularly sensitive to fluctuations in light in the external environment, as light is absorbed and converted to chemical energy to support growth and survival. Photomorphogenesis is the process by which such organisms alter their growth and development in response to fluctuations in light. This process results in changes in growth, cellular development, and metabolism in ways that optimize organismal survival and/or limit damage.

One type of photomorphogenesis that has been long recognized in some cyanobacteria is complementary chromatic adaptation (CCA). During CCA, cyanobacteria alter their pigment or protein composition to maximize light absorption for photosynthesis
(Tandeau de Marsac, 1977), as well as sometimes exhibit changes in filament length and cellular morphology (Bennett and Bogorad, 1973). Fremyella diplosiphon is the most widely studied cyanobacterium capable of CCA. Changes in pigmentation have been associated definitively with increasing photosynthetic potential in this filamentous cyanobacterium (Campbell, 1996).

F. diplosiphon is most sensitive to changes in the prevalence of red and green wavelengths (Bennett and Bogorad, 1973). Under red light (RL) conditions, the organism is blue-green in color due to the accumulation of high levels of the RL-absorbing, blue-colored pigment phycocyanin (PC) in the light-harvesting complexes, or phycobilisomes (PBS), that are connected to the chlorophyll-containing photosynthetic reaction centers (Bennett and Bogorad, 1973). By contrast, under green light (GL) conditions, F. diplosiphon is brick-red in color, due to accumulating high levels of the GL-absorbing, red-colored phycoerythrin (PE) pigment (Bennett and Bogorad, 1973). This light-dependent regulation of pigment accumulation is a photoreversible property controlled by a complex two-component phosphorelay cascade 
that is initiated by the activity of a light-responsive sensor kinase regulator of chromatic adaptation E (RcaE; Kehoe and Grossman, 1996; Terauchi et al., 2004).

In addition to the pigmentation response, light-dependent changes in the lengths of filaments and cellular morphology also occur during CCA in F. diplosiphon (Bennett and Bogorad, 1973). Cells are rounded and shorter and filament length is reduced under RL, whereas under GL cells are longer and brick-shaped, and filaments are longer (Bennett and Bogorad, 1973; Bordowitz and Montgomery, 2008). The changes in cellular morphology and pigmentation are photoreversible (Bennett and Bogorad, 1973; Bordowitz and Montgomery, 2008). The observed morphological changes are controlled in part by the same complex two-component regulatory Rca system that regulates the pigmentation response (Bordowitz and Montgomery, 2008; Bordowitz et al., 2010). However, light-dependent morphological changes controlled by the Rca system were observed earlier than changes in pigment levels (Bordowitz and Montgomery, 2008).

The changes in pigmentation in the accessory complexes of the photosynthetic light-harvesting centers have clear roles in organismal adaptation to changing light conditions-greater light absorption yields increased photosynthetic efficiency, which increases the energy supply for growth and development. The ability to optimize energy production in environments where ambient light changes can lead to selective advantages for organisms exhibiting such abilities (Stomp et al., 2008). However, there has been no clear association of the morphological changes that are observed under changing light conditions with a functionality that might benefit the organism, e.g., buoyancy in the water column or organismal motility. It is noteworthy that in a natural context, the overall levels of light, or light intensities, also change (Postius et al., 2001). The prevalent wavelengths of light change with depth in the water column - red-enriched light at or near the water surface versus green-enriched light at significant depths in the water column. The total light available at depths where green wavelengths dominate can be $10 \%$ or less than that near or at the water surface (Postius et al., 2001).

Previously, we proposed a function for larger F. diplosiphon cells under GL conditions to increase total light absorption in natural environments where overall light levels are lower than near the red-enriched surface (Montgomery, 2008). Therefore, the morphology of these cells may be regulated by light quantity and color in a complex way. To investigate whether the quantity of light plays a significant role in the regulation of cellular morphology, we initiated experiments growing $F$. diplosiphon cultures under increasing fluences of GL over many successive dilutions to determine whether increasing the total available light could signal a decrease in cell size, i.e., allow cellular adaptation, without changing the wavelength of light available. Such an investigation was expected to provide insight into whether the amount of light available, independent of wavelength, impacts cellular morphology in F. diplosiphon and impacts selective pressure to maintain longer cells or cells of larger volume.

\section{MATERIALS AND METHODS STRAINS AND CULTURE CONDITIONS}

Fremyella diplosiphon UTEX 481 was used as wild-type (WT) in this study. Cultures were grown at $28^{\circ} \mathrm{C}$ in $\mathrm{BG}-11$ medium containing $20 \mathrm{mM}$ HEPES, pH 8 (hereafter BG-11/HEPES) with shaking at $\sim 175 \mathrm{rpm}$ under GL at $\lambda \max$ at $530 \mathrm{~nm}$. A Li-Cor light meter (model LI-250, Li-Cor, Lincoln, NE, USA) with a connected Li-Cor quantum sensor (model LI-190SA) was used to measure light intensities.

\section{REITERATIVE DILUTION OF CELLS}

Cultures were initially started from a BG-11/HEPES plate of WT cells growing under white fluorescent room lights at room temperature. After 7 days of growth under GL at 10, 50, 75, or $100 \mu \mathrm{mol} \mathrm{m} \mathrm{m}^{-2} \mathrm{~s}^{-1}$, cultures were diluted to an absorbance at $750 \mathrm{~nm}$ of $\sim 0.1\left(\mathrm{OD}_{750}\right)$. Cells were then returned to the original growth condition and diluted every 7 days to an $\mathrm{OD}_{750}$ of $\sim 0.1$ for five dilutions. Following these initial dilutions, cells were diluted every 3 days to an $\mathrm{OD}_{750}$ of $\sim 0.1$. Cells were imaged after the 5th, 8th, 17th, and 25th dilutions (Figure 1). After this extended iterative dilution series, a culture of cells diluted to an $\mathrm{OD}_{750}$ of $\sim 0.1$ was moved from an intensity of 100 to $10 \mu \mathrm{mol} \mathrm{m}^{-2} \mathrm{~s}^{-1}$ for 3 days to investigate the impact of reversing high light exposure on cellular morphology and physiology.

\section{CONFOCAL MICROSCOPY-BASED ANALYSIS OF CELLULAR MORPHOLOGY}

Slides were prepared and imaged by confocal microscopy as previously detailed (Bordowitz and Montgomery, 2008, 2010). Both differential interference contrast (DIC) and autofluorescence images were acquired using an inverted Axiovert 200 Zeiss LSM 510 Meta confocal laser scanning microscope (CLSM: Carl Zeiss MicroImaging, Thornwood, NY, USA). Cell lengths ( $n \geq 50$ for each condition) were measured, and acquired images were processed using the LSM FCS Zeiss 510 Meta AIM imaging software as detailed (Bordowitz and Montgomery, 2008, 2010).

\section{PIGMENT EXTRACTION AND QUANTIFICATION}

We extracted chlorophyll $a(\operatorname{chl} a)$ and carotenoids from $F$. diplosiphon cells grown in liquid cultures of lower light intensity $\left(10 \mu \mathrm{mol} \mathrm{m}^{-2} \mathrm{~s}^{-1}\right)$, higher light $\left(100 \mu \mathrm{mol} \mathrm{m}^{-2} \mathrm{~s}^{-1}\right)$, and cells shifted from 100 to $10 \mu \mathrm{mol} \mathrm{m}{ }^{-2} \mathrm{~s}^{-1}$ as detailed above. We quantified chlorophyll content as previously described (Bordowitz and Montgomery, 2008) and carotenoid content using equations from Dere et al. (1998).

\section{STATISTICAL ANALYSIS}

Cell length measurement data accumulated from individual experiments were not normally distributed. Therefore, statistical analysis was completed using the Mann-Whitney $U$-test (http://elegans.swmed.edu/ leon/stats/utest.html).

\section{RESULTS}

Fremyella diplosiphon UTEX 481 cells were grown under increasing fluences of GL and reiteratively diluted over defined intervals to allow sequential generations of cells to be exposed to increasing intensities of GL (Figure 1). As cells were cultured for many generations under high intensity GL, the median lengths of cells were observed to decrease. After more than 25 successive dilutions, cells under high intensity GL of 50,75 , or $100 \mu \mathrm{mol} \mathrm{m}^{-2} \mathrm{~s}^{-1}$ were shorter and more rounded in appearance (Table 1; Figure 2) - more similar in shape and nearly identical in length, i.e., 6-7 $\mu \mathrm{m}$, to cells grown under RL (Bordowitz 


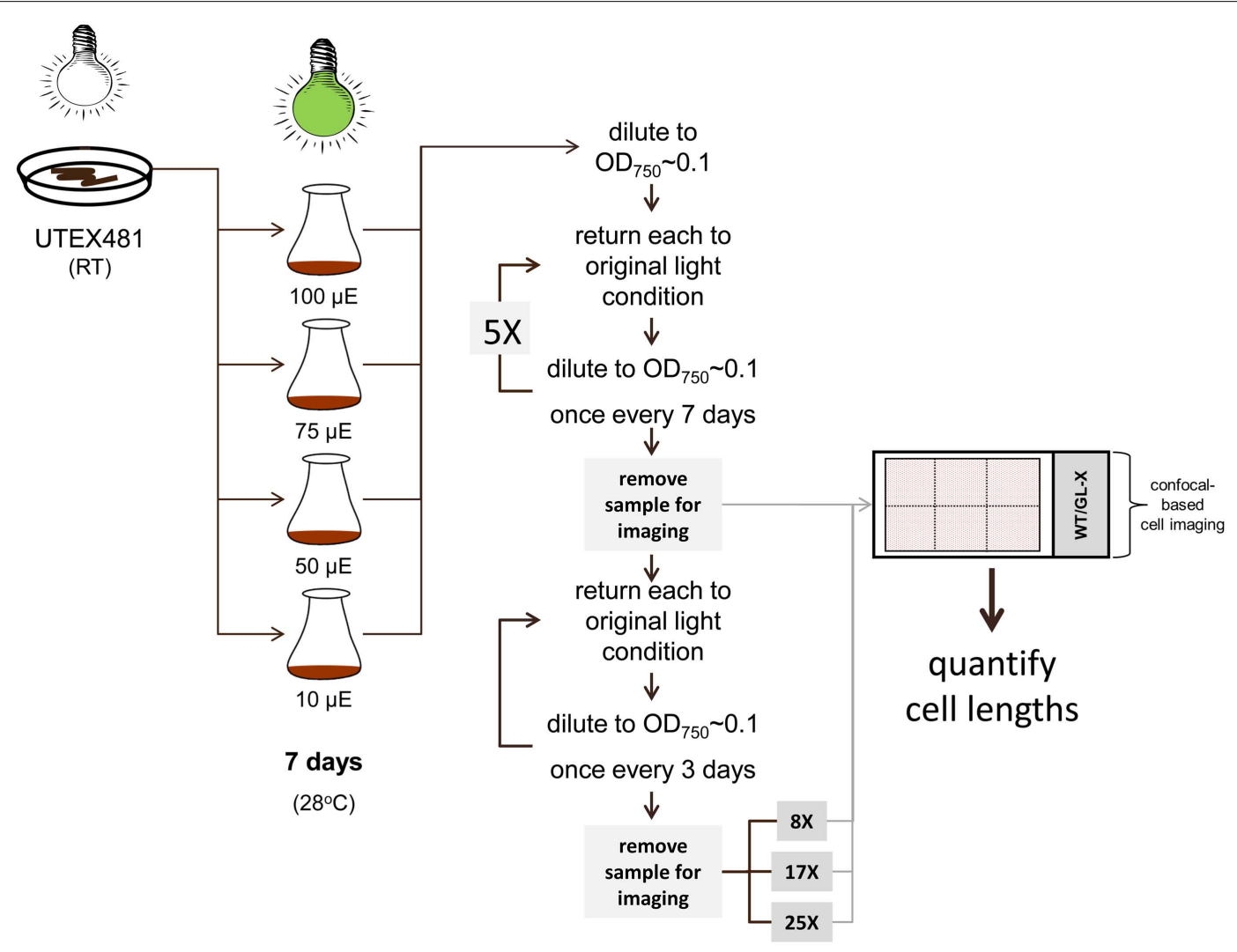

FIGURE 1 | Experimental set-up for examining the impact of different intensities of green light (GL) on the regulation of cellular morphology in the chromatically adapting cyanobacterium Fremyella diplosiphon UTEX 481 wild-type (WT). A liquid culture of $F$. diplosiphon WT was initiated in BG-11 culture medium containing $20 \mathrm{mM}$ HEPES (BG-11/HEPES) from a culture growing on a BG-11/HEPES plate under white fluorescent room light at room temperature (RT). Replicate liquid cultures at an absorbance at $750 \mathrm{~nm}\left(\mathrm{OD}_{750}\right)$ of $\sim 0.1$ were grown under $\mathrm{GL}$ at 10, 50, 75, or $100 \mu \mathrm{mol} \mathrm{m}{ }^{-2} \mathrm{~s}^{-1}$ at $28^{\circ} \mathrm{C}$ with shaking at $\sim 175 \mathrm{rpm}$ for 7 days. Cultures were then diluted to an $\mathrm{OD}_{750}$ of $\sim 0.1$ every 7 days for five consecutive dilutions, followed by dilution to $O D_{750}$ of $\sim 0.1$ every 3 days. Cells were prepared for imaging after 5 th, 8 th, 17 th, and 25 th dilutions.

Table 1 | Median length of cells of Fremyella diplosiphon grown under varying intensities of green light.

\section{Dilutions $^{\mathbf{a}}$}

Cell length $(\mu \mathrm{m})^{b}$

\begin{tabular}{|c|c|c|c|c|}
\hline & \\
\hline & $10 \mu \mathrm{mol} \mathrm{m}^{-2} \mathrm{~s}^{-1}$ & $50 \mu \mathrm{mol} \mathrm{m}^{-2} \mathrm{~s}^{-1}$ & $75 \mu \mathrm{mol} \mathrm{m}^{-2} \mathrm{~s}^{-1}$ & $100 \mu \mathrm{mol} \mathrm{m}^{-2} \mathrm{~s}^{-1}$ \\
\hline 5 & $12.6( \pm 1.9)$ & $11.6( \pm 2.8)$ & $9.3( \pm 1.9)^{* * *, c}$ & $11.5( \pm 2.2)$ \\
\hline 8 & $10.3( \pm 1.0)^{\# \# \#, d}$ & $8.7( \pm 2.0)^{* * *}$ *\#\#\# & $8.4( \pm 1.4)^{* * *}$ & $8.7( \pm 1.4)^{* * *, \# \# \#}$ \\
\hline 17 & $9( \pm 1.1)$ & $7.9( \pm 1.4)^{*}$ & $8.5( \pm 1.6)$ & 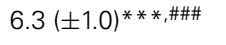 \\
\hline 25 & $9.8( \pm 1.8)$ & $7.4( \pm 0.8)^{* * *}$ & $8( \pm 1.3)^{* * *}$ & $9.8( \pm 1.2)^{\# \# \#, \mathrm{e}}$ \\
\hline
\end{tabular}

${ }^{a}$ Number of consecutive dilutions before imaging.

${ }^{b}$ Numbers represent the median cell length ( $\pm S E$ ) of at least 50 cells that were measured for cultures grown at the indicated fluence of green light.

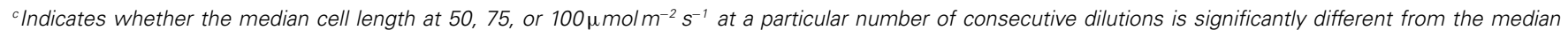
length measured for cells grown at $10 \mu \mathrm{mol} \mathrm{m}{ }^{-2} \mathrm{~s}^{-1}$ at the same number of consecutive dilutions. ${ }^{*} p<0.05 ;{ }^{* * *} p<0.001$.

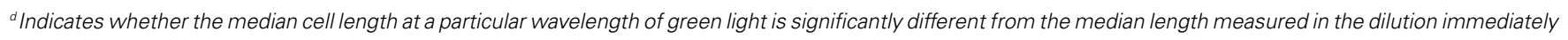
before. ${ }^{*} p<0.05 ;{ }^{\# \# \#} p<0.001$.

${ }^{e}$ Cells appeared stressed and vacuolated.

and Montgomery, 2008; Pattanaik et al., 2011). F. diplosiphon cells at $10 \mu \mathrm{mol} \mathrm{m}^{-2} \mathrm{~s}^{-1}$ of GL stabilized at a longer length with a brick shape, whereas over consecutive dilutions at higher fluences of GL, cells became significantly shorter (Table 1), and appeared more rounded in shape (Figure 2). An exception to the reduced cell length observation was cells under GL of $100 \mu \mathrm{mol} \mathrm{m}^{-2} \mathrm{~s}^{-1}$ after the 25th dilution (Table 1). These cells were still rounded in appearance (Figure 2), yet cell lengths were longer than those for 

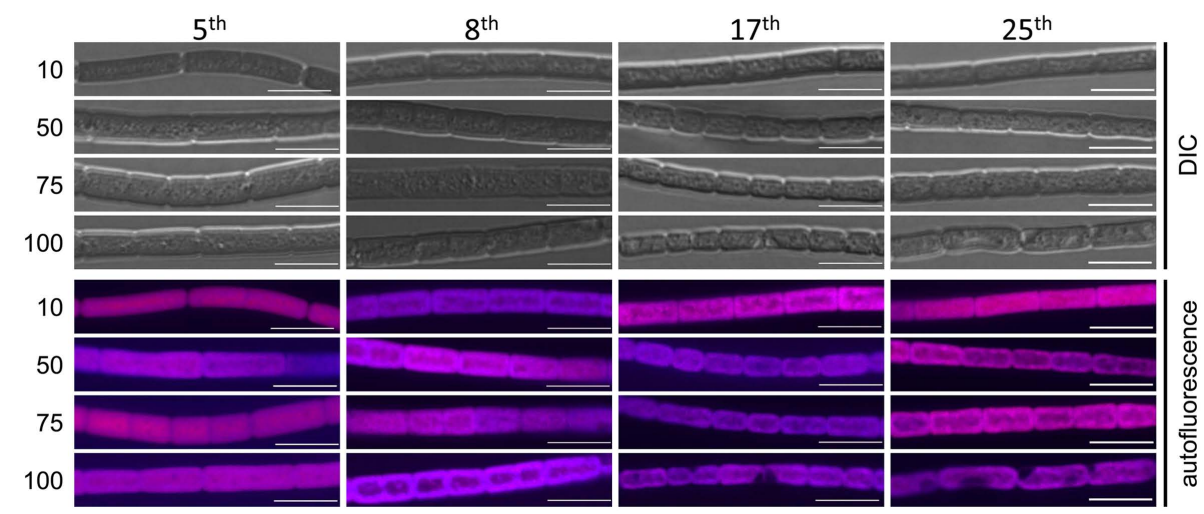

FIGURE 2 | Confocal laser scanning microscopy analyses of cellular morphology of Fremyella diplosiphon UTEX 481 wild-type (WT) strain under green light (GL) conditions of varying light intensity.

F. diplosiphon WT was grown in BG-11 culture medium containing $20 \mathrm{mM}$ HEPES at $10,50,75$, or $100 \mu \mathrm{mol} \mathrm{m}^{-2} \mathrm{~s}^{-1}$ (numbers indicated at left) at $28^{\circ} \mathrm{C}$ with shaking at $\sim 175 \mathrm{rpm}$ as indicated in Figure 1. Representative optical slices from a Z-series of differential interference contrast (DIC) images (upper half) and maximum intensity projection of phycobiliprotein autofluorescence images (lower half) of WT. Numbers of consecutive dilutions $(5,8,17$, or 25$)$ made before imaging are indicated at the top of each column. All images were acquired with a $40 \times$ oil objective with $2 \times$ zoom. Bar represents $10 \mu \mathrm{m}$. the prior two imaged dilutions (Table 1). This increased length appears to be attributed largely to the enlargement that appears related to stress and/or vacuolation. However, these cells were still shorter than the original length before exposure of cells to multiple generations of high intensity GL (Table 1).

To confirm stress-related impacts on the cells that had grown under high intensity GL for many generations, we obtained spectral scans and observed an increased peak at $\sim 480-490 \mathrm{~nm}$ (Figure 3), indicative of carotenoid accumulation (Dere et al., 1998). Light-induced carotenoid accumulation has been associated with stress in cyanobacteria (Gao et al., 2007). We quantified light intensity-dependent accumulation of carotenoids and determined that levels increased under increased light intensity (Table 2). The accumulation of carotenoids was reversible when we moved high GL-grown cells to lower GL of $10 \mu \mathrm{mol} \mathrm{m}^{-2} \mathrm{~s}^{-1}$ for 3 days (Figure 3; Table 2), as was cellular morphology (Figure 4).

\section{DISCUSSION}

Our results support our hypothesis that light intensity plays a significant role in determining the morphology of $F$. diplosiphon cells. Laboratory-based experiments confirm that the adaptation of these cells to both differences of light color (Bennett and Bogorad, 1973; Bordowitz and Montgomery, 2008) and light intensity (Figures 2 and 4) contributes to the change in cellular morphology that can be observed reversibly in these cells. The changes that are observed in cellular morphology in natural environments are, thus, likely to result from a combination of light quality and quantity low intensities of green-enriched light are associated with longer cells, whereas high intensities of red-enriched light are associated with spherical cells. The light-dependent changes in cellular morphology and filament morphology may impact stratification of the organism in the water column - i.e., increased buoyancy and ability to persist higher in the water column may be associated with more rounded cells. A smaller surface area also may be associated with a reduced cell surface area exposed to potential damage by higher light intensities near the surface. Conversely, a larger cell

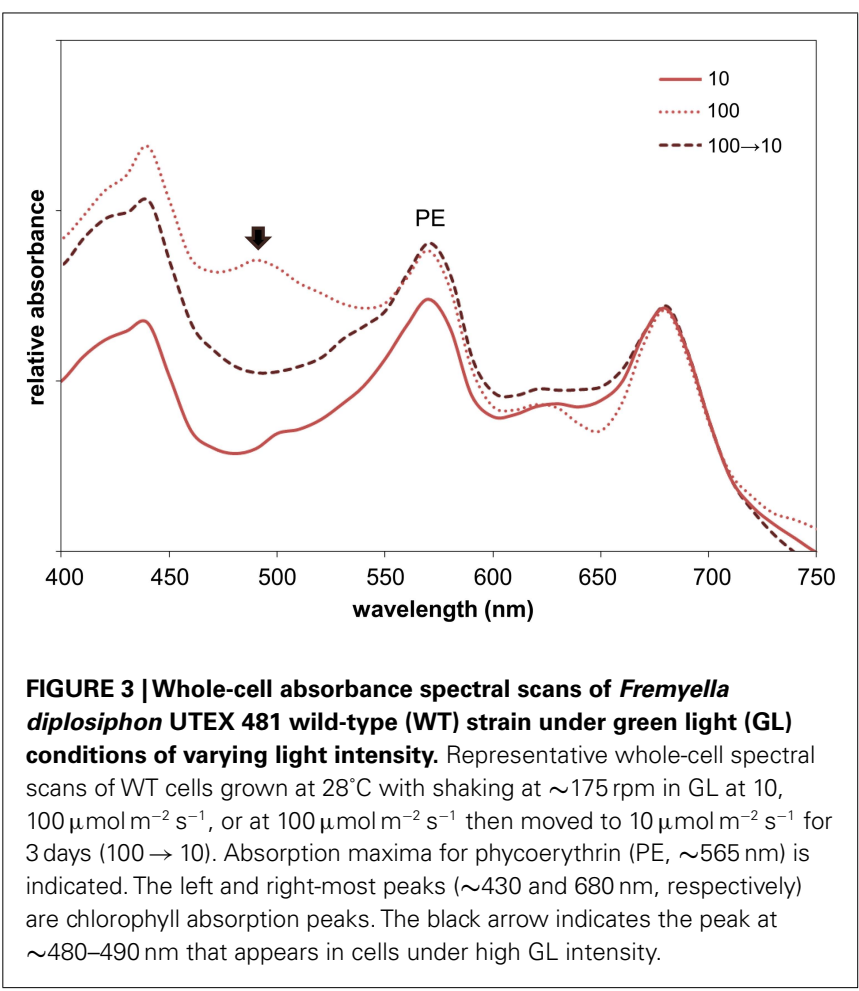

volume associated with green wavelengths and lower intensities of light at lower water column depths may be associated with a greater accumulation of total photosynthetic pigments to increase overall cellular photosynthetic efficiency. Notably, Trichodesmium erythraeum ISM101 is a non-heterocystous diazotrophic cyanobacterium that can live at both the surface and deep in the water column (Andresen et al., 2010). At lower depths, the organism exhibits longer filaments and cells that have a larger diameter (Andresen et al., 2010), indicating that for this organism, lower light intensity is associated with longer filaments and larger cells, 
Table 2 | Phycobiliprotein and photosynthetic pigment quantification.

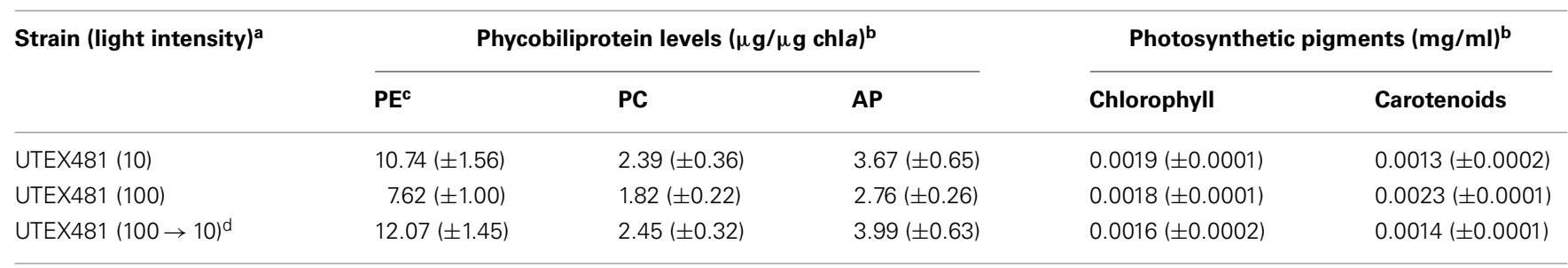

${ }^{a}$ Light intensity units are $\mu \mathrm{mol} \mathrm{m}^{-2} \mathrm{~s}^{-1}$.

${ }^{b}$ Numbers indicate mean $( \pm S D)$ for at least three independent extractions in two independent experiments.

${ }^{c} P E$, phycoerythrin; $P C$, phycocyanin; $A P$, allophycocyanin.

${ }^{d}$ Cultures were grown at $100 \mu \mathrm{mol} \mathrm{m} \mathrm{m}^{-2} \mathrm{~s}^{-1}$ before transfer to $10 \mu \mathrm{mol} \mathrm{m} \mathrm{m}^{-2} \mathrm{~s}^{-1}$ for 3 days.

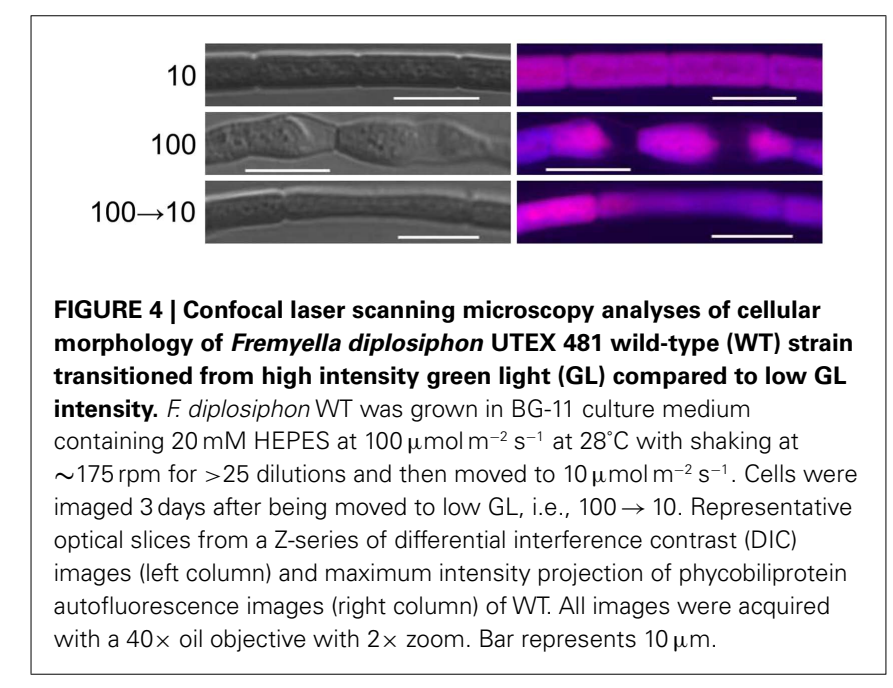

similar to F. diplosiphon. In T. erythraeum, the increased cellular diameter at lower depths and reduced light intensity is associated with an increase in total light absorption per cell (Andresen et al., 2010). Taken together with our observations for F. diplosiphon, these results demonstrate that cyanobacterial cells can regulate morphology based on the quantity of light available, which in addition to prevalent light quality varies at different depths in the water column. Light intensity also impacts cellular elongation in plants for which hypocotyl and stem elongation are controlled by both light quality and light quantity detected by the phytochrome photoreceptors (Ballaré et al., 1991).

Changes in cellular morphology are associated with a number of acclimations and/or adaptations to variations in external environmental parameters in cyanobacteria (reviewed in Singh and Montgomery, 2011). These parameters can include abiotic and biotic factors and/or stresses. The changes in cyanobacterial morphology and physiology that are induced by environmental variations are associated with organismal responses for limiting detrimental impacts of environmental fluctuations, while maximizing survival (for review see Singh and Montgomery, 2011).

The high light adaptation of cellular morphology that we observe in F. diplosiphon is reversible. The exact nature of the molecular changes associated with this adaptation to higher intensity light over several generations requires additional experimentation.
Prior studies in cyanobacteria have identified a number of molecular factors associated with the control of morphology. For example, the presence of bacterial actin MreB has been previously shown to be correlated with rod-shaped cells in the cyanobacterium Anabaena sp. PCC 7120 (Hu et al., 2007). When mreB is mutated in this cyanobacterium, cells are spherical in shape (Hu et al., 2007). Also, mutant studies in the unicellular cyanobacterium Synechococcus sp. strain PCC 7942 demonstrated that lipopolysaccharide assembly is correlated with the regulation of cell division and cellular morphology (Dolganov and Grossman, 1993). Peptidoglycan structure also has been implicated as important for apposite regulation of cell shape in cyanobacteria (Leganés et al., 2005; Lehner et al., 2011). Recent studies in F. diplosiphon demonstrated that the protein FdTonB is associated with the photoregulation of cellular morphology under GL (Pattanaik and Montgomery, 2010). It is not yet clear whether any or all of these components are involved in the observed light intensitydependent changes in morphology in F. diplosiphon. Furthermore, whether the photoregulatory mechanisms associated with the changes observed here under high intensity GL are the same ones invoked during the photoreversible changes in cell shape observed during CCA, e.g., the Rca system (Bordowitz and Montgomery, 2008; Bordowitz et al., 2010), CpeR (Pattanaik et al., 2011), or FdTonB (Pattanaik and Montgomery, 2010), requires additional investigation.

\section{CONCLUDING REMARKS}

The regulation of cellular morphology in F. diplosiphon is correlated with changes in light intensity, suggesting that morphology is regulated as a means of modulating total light absorption per cell that is associated with overall cellular photosynthetic capacity. The mechanisms by which this is accomplished will require further studies. Yet, the association of changes in cellular morphology with light intensity represents an advance in our understanding of the potential purpose(s) of the photoregulation of cellular morphology in cyanobacteria in natural habitats.

\section{ACKNOWLEDGMENTS}

We thank Marco Agostoni for critically reading and commenting on the manuscript and Dr. Shailendra Singh for imaging of cells for the reversal experiments. Bagmi Pattanaik and Melissa Whitaker were supported by the U.S. Department of Energy 
(Chemical Sciences, Geosciences and Biosciences Division, Office of Basic Energy Sciences, Office of Science, grant no. DE-FG0291ER20021 to Beronda L. Montgomery) and participation by

\section{REFERENCES}

Andresen, E., Lohscheider, J., Setlikova, E., Adamska, I., Šimek, M., and Küpper, H. (2010). Acclimation of Trichodesmium erythraeum ISM101 to high and low irradiance analysed on the physiological, biophysical and biochemical level. New Phytol. 185, 173-188.

Ballaré, C. L., Scopel, A. L., and Sánchez, R. A. (1991). Photocontrol of stem elongation in plant neighbourhoods: effects of photon fluence rate under natural conditions of radiation. Plant Cell Environ. 14, 57-65.

Bennett, A., and Bogorad, L. (1973). Complementary chromatic adaptation in a filamentous blue-green alga. J. Cell Biol. 58, 419-435.

Bordowitz, J. R., and Montgomery, B. L. (2008). Photoregulation of cellular morphology during complementary chromatic adaptation requires sensor-kinase-class protein RcaE in Fremyella diplosiphon. J. Bacteriol. 190, 4069-4074.

Bordowitz, J. R., and Montgomery, B. L. (2010). Exploiting the autofluorescent properties of photosynthetic pigments for analysis of pigmentation and morphology in live Fremyella diplosiphon cells. Sensors 10, 6969-6979.

Bordowitz, J. R., Whitaker, M. J., and Montgomery, B. L. (2010). Independence and interdependence of the photoregulation of pigmentation and development in Fremyella diplosiphon. Commun. Integr. Biol.3, 151-153.

Campbell, D. (1996). Complementary chromatic adaptation alters photosynthetic strategies in the cyanobacterium Calothrix. Microbiology 142, 1255-1263.

Dere, S., Güneş, T., and Sivaci, R. (1998). Spectrophotometric determination of chlorophyll - a, b and total carotenoid contents of some algae species using different solvents. Turk. J. Bot. 22, 13-18.

Dolganov, N., and Grossman, A. R. (1993). Insertional inactivation of genes to isolate mutants of Synechococcus sp. strain PCC 7942: isolation of filamentous strains. J. Bacteriol. 175, 7644-7651.

Gao, K., Yu, H., and Brown, M. T. (2007). Solar PAR and UV radiation affects the physiology and morphology of the cyanobacterium Anabaena sp. PCC 7120. J. Photochem. Photobiol. B Biol. 89, 117-124.

Hu, B., Yang, G., Zhao, W., Zhang, Y., and Zhao, J. (2007). MreB is important for cell shape but not for chromosome segregation of the filamentous cyanobacterium Anabaena sp. PCC 7120. Mol. Microbiol. 63, 1640-1652.

Kehoe, D. M., and Grossman, A. R. (1996). Similarity of a chromatic adaptation sensor to phytochrome and ethylene receptors. Science 273, 1409-1412.

Leganés, F., Blanco-Rivero, A., Fernández-Piñas, F., Redondo, M., Fernández-Valiente, E., Fan, Q., Lechno-Yossef, S., and Wolk, C. P. (2005). Wide variation in the cyanobacterial complement of presumptive penicillin-binding proteins. Arch. Microbiol. 184, 234-248.

Beronda Montgomery by a CAREER award from the National Science Foundation (grant no. MCB-0643516 to Beronda L. Montgomery).

Lehner, J., Zhang, Y., Berendt, S., Rasse, T. M., Forchhammer, K., and Maldener, I. (2011). The morphogene AmiC2 is pivotal for multicellular development in the cyanobacterium Nostoc punctiforme. Mol. Microbiol. 79, 1655-1669.

Montgomery, B. L. (2008). Shedding new light on the regulation of complementary chromatic adaptation. Cent. Eur. J. Biol. 3 , 351-358.

Pattanaik, B., and Montgomery, B. L. (2010). FdTonB is involved in the photoregulation of cellular morphology during complementary chromatic adaptation in Fremyella diplosiphon. Microbiology 156, 731-741.

Pattanaik, B., Whitaker, M. J., and Montgomery, B. L. (2011). Regulation of phycoerythrin synthesis and cellular morphology in Fremyella diplosiphon green mutants. Biochem. Biophys. Res. Commun. 413, 182-188.

Postius, C., Neuschaefer-Rube, O., Haid, V., and Böger, P. (2001). N2-fixation and complementary chromatic adaptation in non-heterocystous cyanobacteria from Lake Constance. FEMS Microbiol. Ecol. 37, 117-125.

Singh, S. P., and Montgomery, B. L. (2011). Determining cell shape: adaptive regulation of cyanobacterial cellular differentiation and morphology. Trends Microbiol. 19, 278-285.

Stomp, M., Van Dijk, M. A., Van Overzee, H. M. J., Wortel, M. T., Sigon, C. A. M., Egas, M., Hoogveld,
H., Gons, H. J., and Huisman, J. (2008). The timescale of phenotypic plasticity and its impact on competition in fluctuating environments. Am. Nat. 172, E169-E185.

Tandeau de Marsac, N. (1977). Occurrence and nature of chromatic adaptation in cyanobacteria. J. Bacteriol. 130, 82-91.

Terauchi, K., Montgomery, B. L., Grossman, A. R., Lagarias, J. C., and Kehoe, D. M. (2004). RcaE is a complementary chromatic adaptation photoreceptor required for green and red light responsiveness. Mol. Microbiol. 51, 567-577.

Conflict of Interest Statement: The authors declare that the research was conducted in the absence of any commercial or financial relationships that could be construed as a potential conflict of interest.

Received: 28 March 2012; accepted: 17 April 2012; published online: 07 May 2012.

Citation: Pattanaik B, Whitaker MJ and Montgomery BL (2012) Light quantity affects the regulation of cell shape in Fremyella diplosiphon. Front. Microbio. 3:170. doi: 10.3389/fmicb.2012.00170

This article was submitted to Frontiers in Microbial Physiology and Metabolism, a specialty of Frontiers in Microbiology. Copyright (c) 2012 Pattanaik, Whitaker and Montgomery. This is an open-access article distributed under the terms of the Creative Commons Attribution Non Commercial License, which permits noncommercial use, distribution, and reproduction in other forums, provided the original authors and source are credited. 